\title{
Retraction Note: SVM-based water pollution detection and economic benefit analysis of aquaculture industry
}

\author{
Yong Zhang ${ }^{1}$. Weifeng Ren ${ }^{1}$. Chengqun $\mathrm{Hu}^{1}$
}

Published online: 9 December 2021

C) Saudi Society for Geosciences 2021

Retraction Note: Arabian Journal of Geosciences (2021) 14: 1583 https://doi.org/10.1007/s12517-021-07943-1

The Editor-in-Chief and the Publisher have retracted this article because the content of this article is nonsensical. The peer review process was not carried out in accordance with the Publisher's peer review policy. Authors Yong Zhang and Weifeng Ren have not responded to correspondence regarding this retraction. The Publisher has not been able to obtain a current email address for author Chengqun Hu.

The original article can be found online at https://doi.org/10.1007/ s12517-021-07943-1.

Weifeng Ren

mail1262021@126.com

1 Shijiazhuang Posts and Telecommunications Technical College, Shijiazhuang 050000, Hebei, China 